\title{
GH Receptor Antagonist: Mechanism of Action and Clinical Utility
}

\author{
Sowmya K. Surya and Ariel L. Barkan \\ Division of Endocrinology, University of Michigan Hospitals, 3920 \\ Taubman Center, Box 0354, 1500 E. Medical Center Drive, \\ Ann Arbor, MI 48109, USA
}

\section{Key Words. acromegaly, GH receptor antagonists, Pegvisomant}

This review focuses on the development of GH receptor antagonist as a novel agent for treatment of acromegaly, its mechanism of action and potential areas of use. A brief overview of acromegaly, its diagnosis and existing medical, surgical and radiotherapy options of treatment is necessary to justify the addition of yet another therapeutic modality to the already vast therapeutic armamentarium.

\section{Introduction}

Acromegaly is a multisystem disease due to chronic hypersecretion of growth hormone $(\mathrm{GH})$ from a pituitary adenoma [1]. The resultant increase in insulin like growth factor (IGF-1) causes somatic overgrowth whereas elevated $\mathrm{GH}$ on its own promotes certain metabolic derangements such as glucose intolerance or diabetes. Extension of the pituitary tumor outside the confines of the sella may cause ophthalmoplegia and chiasmal compression. The mortality and morbidity of acromegaly are determined by GH/IGF-1 induced end organ damage such as cardiomyopathy, arrthymias, sleep apnea, diabetes and osteoarthritis in addition to mass effects of tumor and accompanying hypopituitarism [2-5].

\section{Diagnosis}

The diagnosis of acromegaly essentially rests on a combination of physical findings, elevated GH and IGF-1 levels and inability of an oral glucose load to suppress plasma GH [6,7]. The biochemical criteria for the diagnosis and surveillance of acromegaly have changed over the years as a result of several epidemiological studies analyzing the mortality of acromegaly as a function of prevailing $\mathrm{GH}$ milieu $[7,8]$.

Whereas many treated and even newly diagnosed patients may have random or mean daily GH levels within the "normal" range, the trough or interpulse GH concentrations are uniformly elevated in patients with active disease
[9]. This feature of GH hypersecretion will be obviously missed unless a frequent (Q10-20 min) and prolonged (12-24 hr) blood sampling is performed. On the other hand, a single value of plasma IGF-1 faithfully reflects both the total daily $\mathrm{GH}$ output as well as the prevailing pattern of GH secretion [8,9]. Plasma IGF-1 needs to be interpreted according to strict age/gender adjusted normative values. The criteria for glucose suppressed GH have also changed markedly. According to strict contemporary criteria, plasma $\mathrm{GH}$ needs to fall below $0.2-0.25 \mathrm{ug} / \mathrm{l}$ to be defined as a manifestation of a normal physiological response [10-12]. Failure of GH to suppress normally (even in the presence of normal IGF-1) may potentially predict higher probability of recurrence. Thus, both GH (glucose suppressed) and IGF-1 are valuable parameters to be assessed in patients with acromegaly. Plasma GH is a more sensitive indicator of acute changes in tumor activity (i.e, after surgery, radiotherapy, dopamine and somatostatin analogues) whereas IGF-1 is an infinitely better parameter of overall normalcy of GH secretion and the clinical activity of acromegaly (arthropathy, soft tissue volume, perspiration, sleep apnea etc). Both GH $(<1-2.5$ ug/l) and IGF-1 (age/gender normal) have been shown to predict normalization of subsequent mortality rates [4,5]. The size and the invasiveness of the pituitary adenoma is best assessed by MRI.

Thus, the goals of therapy can be subdivided into 3 categories:

(1) Primary: normalization of plasma IGF-1 and abolition of the mass effects of the tumor.

(2) Secondary: therapy of associated morbidities (arthropathy, diabetes, arrhythmias etc.) and replacement of missing pituitary hormones in case of hypopituitarism.

(3) Ultimate: normalization of mortality rates and prevention of recurrence.

Corresponding author: Ariel L. Barkan

E-mail: abarkan@umich.edu 


\section{Practical Aspects of Treatment of Acromegaly}

Therapeutic choices for management of acromegaly are largely dictated by age and general health of the patient as well as efficacy, complications and risks of a particular therapeutic modality. General consensus [12] is that trans-sphenoidal adenomectomy is the first line therapy followed by medical therapy if the former is not curative. In some patients with unacceptable cardiovascular, surgical or anesthetic risks and adenomas not impinging on the optic chiasm, or those whose tumor is surgically inaccessible (e.g., largely confined to the cavernous sinus), primary medical therapy may be offered. If a maximum dose of medications fails to achieve remission and the tumor continues to grow, radiotherapy needs to be considered. Reoperation or treatment with $\mathrm{GH}$ receptor antagonist should be considered for patients resistant to surgical or medical approaches.

\section{Surgery}

Surgery is the cornerstone of therapy and procedure of choice for initial management. The success of surgery depends on the experience of the surgeon on the one hand and on the characteristics of the tumor (size, invasiveness, consistency) on the other hand. The former is exemplified by the wide variability of proportion of patients with post-operative $\mathrm{GH}<2.5 \mathrm{ug} / \mathrm{l}$ in different treatment centers $[13,14]$. The overall success rate even in the best neurosurgical centers is about $50 \%[13,14]$. Some $85 \%$ of patients with microadenomas achieve normal IGF-1 levels post surgery, but the success rate plummets in patients with macroadenomas. Invasiveness of the tumor into the surrounding tissues (cavernous sinus especially) precludes curative outcome.

\section{Complications of Surgery}

Surgical damage of pituitary can lead to permanent hypopitutarism and result in need for lifelong hormone replacement. CSF rhinorrhea, visual impairment, sinusitis and hemorrhage are seen in a small number of patients. The likelihood of complications is directly related to the experience of the neurosurgeon, the size of the tumor and is more common after subfrontal rather than transsphenoidal surgery.

\section{Radiotherapy}

Radiation has been used as a therapeutic modality for acromegaly since 1909. Current modalities include conventional external radiotherapy (XRT) and stereotactic approaches (proton beam, gamma knife and LINAC). XRT is usually administered over four to six weeks in daily fractions to a total dose of 45-50 Gy. In most patients GH levels fall by about $50 \%$ in the first $1-2$ years and continue to decrease slowly thereafter $[15,16]$. Medical therapy is often required to bridge the latency period until radiotherapy becomes effective. Multiple studies have reported declines in GH levels for up to 20-25 years, with ultimate $\mathrm{GH}$ values below $5 \mathrm{ug} / \mathrm{l}$ in $70-90 \%$ of cases [16]. Review of published data $[17,18]$ however have shown that radiation therapy is much less effective than previously thought when its efficacy is judged by modern criteria. Radiation therapy was found to normalize IGF- 1 levels in only $1 / 3$ of patients after 10 years $[18,19]$. Understandably the patients with the highest initial GH levels fare the worst. Hypopituitarism develops in $50-70 \%$ of patients and in rare cases XRT may cause optic nerve damage and ophthalmoplegia. Radiation vasculopathy increases the risk of cerebrovascular accidents by 2-4 fold [20] and there is a $1-2 \%$ risk of developing radiation induced malignant tumors [21] incidence of neurocognitive deficits with significant memory loss and depression had never been quantified but many post radiation patients have these complaints.

\section{Stereotactic radiosurgery (SRS)}

Stereotactic radiosurgery modalities include use of a linear accelerator, gamma knife and proton beam [22]. Their advantage over XRT is largely limited to the need for only a single dose procedure. Rigid target fixation and computerized image acquisition optimize targeting and minimize radiation field scatter.

Although only limited data are available and the duration of follow-up was relatively short, summary of available data $[19,23]$ does not demonstrate any superiority of stereotactic radiosurgery over conventional radiotherapy as judged by final IGF-1 values. It is also still uncertain whether SRS has a more rapid effect. Since only small tumor remnants are suitable for SRS, the low initial GH levels in this population of patients introduce a bias in favor of a seemingly more rapid normalization of plasma $\mathrm{GH}$. The rate of side effects is comparable between the two modalities, but the risk of local neurotoxicity (chiasmal or temporal lobe damage) may be higher with SRS if the planning was faulty.

\section{Dopamine Receptor Agonists}

Dopamine stimulates GH release in normal individuals but paradoxically inhibits it in subjects with GH secreting adenoma. Review of meta- analysis of published studies [24] showed that daily doses of bromocriptine at 5-80 mg/day in 549 patients normalized IGF-1 in less than $10 \%$ of patients. Newer agents like quinagolide and cabergoline 
have longer duration of action, higher specificity for the dopamine receptor and greater efficacy and have been shown to be better tolerated [25]. The largest study of patients with Cabergoline showed normalization of IGF1 levels in 39\% of patients [25] but other groups failed to confirm these results. Overall, dopamine agonists are only rarely effective, but their oral route of administration makes them attractive enough to attempt their use on at least a trial basis.

\section{Somatostatin Analogues}

Five somatostatin receptor subtypes, SSTR1-5, each encoded on a separate chromosome are responsible for a variety of heterogenous effects of somatostatin (SRIF) in different organs and tissues. SSTR2 and 5 are predominant subtypes expressed in the normal pituitary and inhibit $\mathrm{GH}$ and TSH release. In vitro, somatostatin retains its inhibitory effect on GH secreting tumors and this has led to the development of somatostatin analogs for clinical use in the treatment of acromegaly [26]. Octreotide is an octapeptide that is almost selectively SSTR2 specific. It has in vivo half life of $2 \mathrm{~h}$, and inhibits $\mathrm{GH}$ secretion with 45 fold greater potency than native SRIF [27]. A single sc injection suppresses $\mathrm{GH}$ secretion for up to $8 \mathrm{~h}$.

Octreotide LAR is a formulation prepared as slowly bio-degrading polymer which allows prolonged release of the drug. Steady state conditions are achieved after 2-3 monthly I.M injections at which time the maximal suppression of GH and IGF-1 can be observed. Although recommended by the manufacturer to be given as monthly doses, the long half life often enables once every 6-8 week dosing.

Lanreotide is available in Europe and is another long acting somatostatin analog administered as intramuscular injections once every 7-14 days. Lanreotide autogel, a new galenic form is a pure aqueous solution of lanreotide and can be administered by deep sc injections every 28 days [28].

All SRIF analogs inhibit GH secretion and IGF-1 levels in patients with acromegaly. Their efficacy is dose dependant and inversely proportional to baseline $\mathrm{GH}$ concentrations $[28,29]$ Overall they normalize IGF- 1 concentrations in up to $60 \%$ of patients. Additionally they are capable of shrinking pituitary somatotropinomas in the majority of cases, although the degree of shrinkage is highly variable, between 20-80\% [30]. Most importantly, they effectively prevent future tumor growth. Some patients however are either insensitive to the drug or have unacceptable degree of side effects.

A new analog, SOM 230 binds to all the SSTR's except subtype 4 and has 40 higher fold affinity for SSRT5 than octreotide. SOM 230 is more potent in inhibiting GH secretion compared to octreotide in cultured rat pituitary cells and in vivo in animals [31]. This novel peptide is currently in Phase 2 trials.

The main side effects of all somatostatin analogs are diarrhea, nausea, abdominal pain and pain at the injection site. Gallstones which are usually asymptomatic are seen in $3-12 \%$ of patients [29]. Their formation is thought to be due to inhibition of gall bladder emptying and CCK secretion. Long acting somatostatin analogs were equally effective as primary or secondary therapy. Symptoms such as soft tissue swelling, increased perspiration, fatigue and arthritis improved in 50-100\% of patients when the drug was used as primary therapy in acromegaly [28,29]. Headache appears to improve better with short acting than long acting analogs. Manifestation of cardiovascular disease, primarily $\mathrm{LVH}$ and ejection fraction improve with normalization of IGF-1. There is also reduction of joint thickening and sleep apnea.

In summary, surgery and radiation are potentially curative modalities and carry a one time price tag. However they are either very operator dependant (surgery) or slow acting and neurotoxic (radiation). Dopamine agonists are very ineffective and may be used in occasional patients only. SRLs accomplish both biochemical and tumor restraining goals of therapy but are not always effective and quite expensive in the long run.

Importantly, all of the above modalities work at the level of the tumor and their efficacy is determined by the peculiarities of the neoplastic tissue: rate of growth, fibrosis, radioresistance, presence of dopamine or somatostatin receptors.

Alternative approaches to treatment of acromegaly would be aimed at preventing GH action rather than suppressing its secretion. Two experimental models-fasting $[32,33]$ and estrogen therapy $[34,35]$ provided initial clues to that approach.

Early studies have shown that high doses of estrogen seem to offer clinical benefits to patients with acromegaly $[34,35]$. Subsequently it was shown that estrogen antagonizes GH signal transduction by suppressing JAK-2 phosphorylation [36]. Raloxifene, a SERM, suppressed plasma IGF-1 in acromegalic women [37] and men [38], but IGF-1 normalization was only seldom seen.

Fasting was shown to decrease the abundance of GHR mRNA in the liver and other tissues in rats and Ho et al. have shown that fasting lowers circulating IGF-1 in patients with acromegaly at the same rate as in normal controls [33]. Both after fasting and after estrogen plasma GH increases as a result of disruption of the negative feedback loop.Thus fasting and estrogen can lower plasma IGF-1 in patients with acromegaly by lowering GHR number or by interfering with the GH signal transduction. Unfortunately neither of these modalities can be used practically. 


\section{Pegvisomant}

The scientific discovery of GH receptor antagonist Pegvisomant began 15 years ago with the elucidation of the structure- function relationship of $\mathrm{GH}$ and its receptor. GH is a 22 Kda polypeptide with 191 amino acids, 2 disulphide bonds and four alpha helices. It is synthesized in the somatotrophic cells of the anterior pituitary and is central to the regulation of growth and differentiation primarily modulating gene expression and metabolism in target tissues. It has numerous other biological effects including enhancement of milk production, nitrogen retention, lipolysis and diabetogenic effects. Although GH may have direct metabolic effects on peripheral tissues most of its growth promoting effects are mediated by IGF-1 (insulin like growth factor), a member of the insulin like peptide family. GH binding to the extracellular portion of the receptor is followed by the dimerization of GHR and initiation of the GH signaling $[39,40]$. The GH molecule has 2 separate receptor binding domains: site 1 and site 2 . The secondary structure of GH consists of four $\alpha$ helix core with 2 disulphide bonds, such that noncontiguous regions of the aminoacid chain contribute to the two binding regions. Site 1 is made up of the loop between aminoacid residues 54 and 74 at the $C$ terminal half of helix four and $N$ terminal region of helix one. The $N$ terminal residues of the first and third helices contribute to binding site 2 . Once GH binds to the initial GH receptor via site 1, a second identical receptor is recruited by site 2 , leading to receptor dimerization and subsequent cellular activation (Fig. 1). Glycine in the third $\alpha$ helix of GH is particularly important for GH's biological activity. If it is replaced with variety of other amino acids, GH is converted from growth enhancer to a growth suppressor or GH antagonist (Fig. 2). Kopchick et al. [39-41] demonstrated that the GH antagonist could inhibit the cell differentiation promoting activities of GH on mouse pre-adipocytes at equimolar concentrations. The lipolytic and insulin like activities of $\mathrm{GH}$ were completely inhibited by 10 fold excess of $\mathrm{GH}$ antagonist using rat adipose tissues. Transgenic mice that express a $\mathrm{GH}$ mutant with the so called perfect amphiphilic helix 3 have decreased circulating insulin like growth factor (IGF-1) concentrations and exhibit a dwarf phenotype. By combining site specific mutagenesis of the GH gene with an in vivo assay of the ability of $\mathrm{GH}$ analogs to regulate growth of transgenic mice, a GH antagonist was discovered. Thus, $\mathrm{GH}$ antagonists acted to inhibit $\mathrm{GH}$ action both in vivo and in vitro.

\section{Creation of pegvisomant}

Pegvisomant is a $\mathrm{GH}$ analog that includes single amino acid substitution at position 120 within binding site 2 which prevents its binding to GH receptor [41] (Fig. 2).

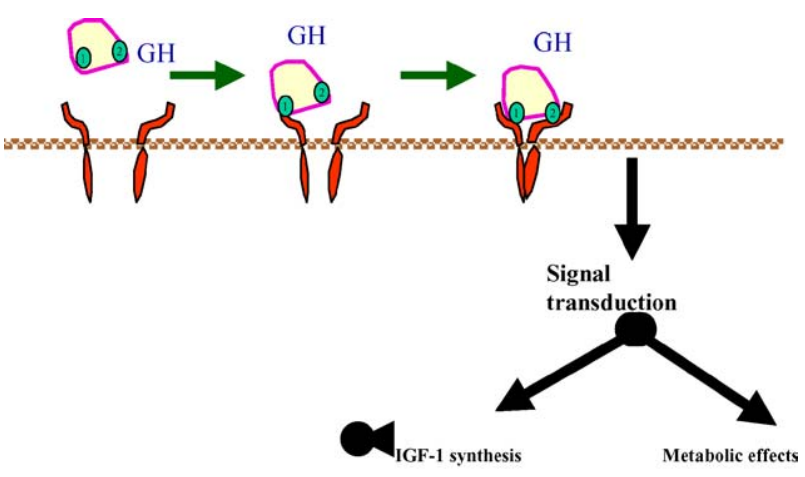

$\mathrm{GH}=$ Growth hormone

Fig. 1. Schematic representation of GH-GHR interaction and biological effects.

The additional changes included 8 amino acid substitutions within binding site 1 that actually increase its binding properties and PEG moieties that increase half life and reduce immunogenecity of the molecule. When the resulting GHR antagonist molecule- the original substitution of Gly 120 at site 2 as well as eight mutations in site 1- was combined with PEG 5000, the final molecule was shown to maintain GHR binding and antagonistic properties with extended half life of 100 hours. The generic name is pegvisomant and trade name is Somavert.

\section{Pegvisomant Efficacy}

The relatively long half life of Pegvisomant allows once daily subcutaneous administration. Pegvisomant, if given in sufficient quantities, has been shown to normalize IGF1 levels in almost all patients with acromegaly in a dose dependant fashion. In a randomized trial [43] of 112 patients for 12 weeks with increasing doses of pegvisomant 10,15 and $20 \mathrm{mg}$ per day, it was found that serum IGF1 levels normalized in $90 \%$ of patients with acromegaly with significant improvement in signs and symptoms such as soft tissue swelling, excessive perspiration and fatigue [43-45]. In longer term studies, pegvisomant decreased IGF-1 levels in $97 \%$ of 90 patients treated for more than 12 months using up to $40 \mathrm{mg} /$ day [47]. Also corrected were the metabolic defects of acromegaly such as insulin resistance and changes in cortisol and lipid metabolism $[48,49]$ $\mathrm{GH}$ induces gluconeogenesis and lipolysis, resulting in increased blood glucose and FFA and this is reversible in patients with acromegaly during pegvisomant therapy $[43,47]$. A single injection of pegvisomant rapidly suppressed IGF-1 levels by $31 \%$ and enhanced GH secretion. An increase in plasma $\mathrm{GH}$ within days of initiating chronic Pegvisomant therapy was also observed [47]; within 2 weeks, plasma GH concentrations plateaued at 2-3 times basal levels. The decrease in IGF-1 levels correlated with the increase in GH burst amplitude [50]. 


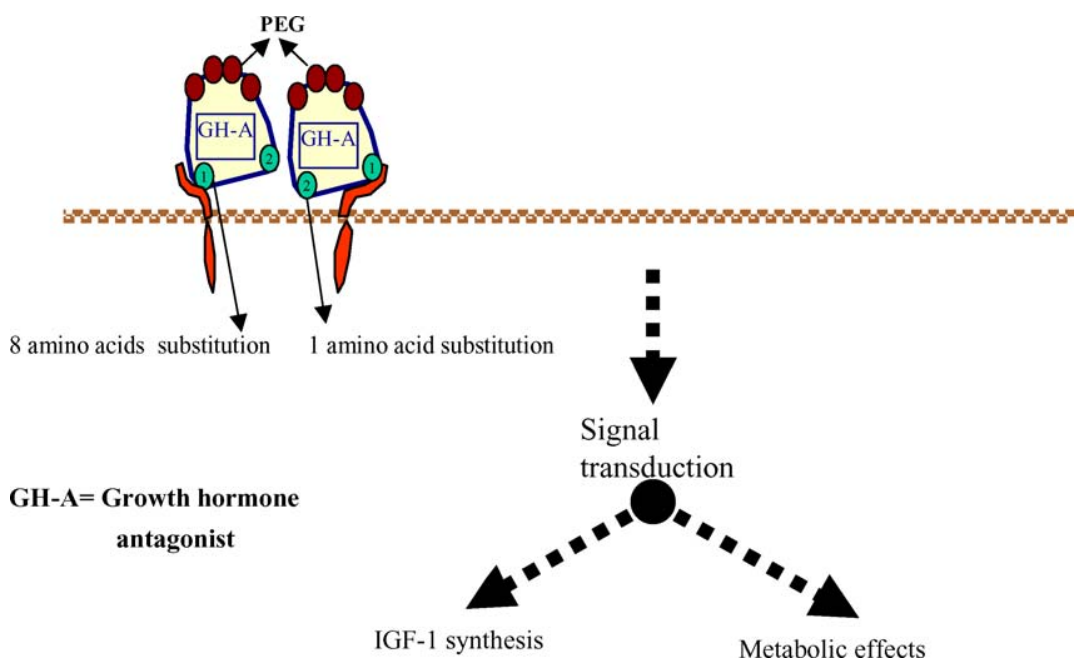

Fig. 2. Schematic representation of GH-GH-A-GHR interaction and inhibition of biological effects.

\section{Long term clinical efficacy}

A second study [47] was done after the initial 12 week trial and pegvisomant injections were given to $160 \mathrm{pa}-$ tients for 6 months $(n=131), 12$ months $(n=90)$ and for 18 months $(n=39)$ to evaluate the long term efficacy. Development of GH antibodies was evaluated periodically and MRI of the pituitary was done every 6 months to evaluate potential changes in tumor size. No change in mean tumor size was observed, however GH levels increased in the first 2 weeks of therapy. There was no additional increase in $\mathrm{GH}$ levels thereafter and no evidence of tachyphylaxis. Of note, the serum IGF-1 levels normalized in $97 \%$ of patients with a dose of up to $80 \mathrm{mg} /$ day for 12 months.

Long term therapy with pegvisomant caused improvement in metabolic parameters of acromegaly such as reduction of fasting insulin levels and corresponding fall in serum glucose concentrations [51,52]. Van der Lely et al. [47] reported a significant decrease in fasting serum insulin and glucose levels in patients treated with pegvisomant for 18 months. Rose and Clemmons [52] observed that in 4 out of five patients normalization of IGF levels was accompanied by improvement in insulin sensitivity. This was associated with a fall in fasting insulin levels enabling one of the patients to discontinue oral hypoglycemic agent, another one to switch from insulin to oral anti- diabetic agent and the third one to decrease insulin dose by $50 \%$. In another study, conversion of patients from LAR to pegvisomant resulted in significant fall in HbA1C and glucose levels [51]. Thus GH antagonist therapy lowered insulin levels and glucose and improved insulin sensitivity.

There was development of anti pegvisomant antibodies in $17 \%$ of patients, but titres were low and not accompanied by tachyphylaxis. Elevation of hepatic enzymes had been observed in less than $1 \%$ of patients and returned to normal with the cessation of pegvisomant. Also the tumor size increased only in 2 of the patients requiring further therapy with irradiation but these tumors appeared to be invasive at the outset.

Since then additional 8 patients out of a total cohort of about 600 patients were shown to increase the tumor size during pegvisomant therapy. It is still unknown whether the decline in IGF-1 was the causative factor (analogous to the development of Nelson's syndrome) or just a propensity of some tumors to grow irrespective of any external influence.

Thus, overall, pegvisomant is remarkably effective in normalizing plasma IGF-1 and abrogating the metabolic effects of elevated GH. The more widespread use of this drug is limited by its cost, the relative inconvenience of daily injections (as opposed to monthly administration of somatostatin analogues), lack of efficacy against the headache and the uncertainity about its effects on tumor progression.

\section{Safety and Tolerability}

In summary, Pegvisomant lowered IGF-1 levels and improved insulin sensitivity in patients with acromegaly. There is no evidence of tachyphylaxis [47] although there is some development of antibodies. The general guidelines for follow-up include monitoring tumor size with MRIs semiannually and then yearly for the first few years unless the tumor is known to be actively growing in which case earlier exams may be required. Also visual perimetry is recommended for patients with visual problems before surgery and in patients with macroadenomas and residual extrasellar tumors after surgery. 
The main side effects of Pegvisomant therapy are injection site reactions (10\%), deranged liver function tests (elevated AST and ALT) and increase in pituitary tumor size $[46,47]$. The latter two side effects occur in less than $1 \%$ of patients.

\section{Future Directions}

Indirect and early experimental data suggest that GH receptor antagonists can be potentially used not only in the treatment of acromegaly but also in cancer and diabetes.

\section{Diabetic retinopathy}

Modulation of IGF-1/GH axis in diabetic patients have implications in microvascular complications of diabetes as was first noted in patients with pituitary ablation that arrested the progression of diabetic retinopathy. GH has been shown to stimulate proliferation of human retinal microvascular endothelial cells in vitro. There has been a positive correlation between GH concentration and progression of diabetic retinopathy [53]. Over expression of IGF-1 in retinal tissue promotes retinopathy and GH receptor antagonists protect from ischemia induced retinal neovascularization. The role of GH in diabetic retinopathy was studied by Smith et al. using dwarf transgenic mice expressing $\mathrm{GH}$ receptor antagonist gene and normal mice given inhibitor of GH secretion, MK 678 [53]. In both groups retinal neovascularization was inhibited. This was inversely proportional to the decline in serum IGF-1 levels and was reversed by addition of exogenous IGF-1. This suggests that systemic inhibition of GH or IGF-1 or both may have a therapeutic role in preventing retinopathy.

However direct human study in patients with established diabetic retinopathy failed to substantiate the beneficial effects of pegvisomant on disease progression. Beck et al. [54] studied effects of GH receptor antagonist in 25 patients with diabetes mellitus and proliferative retinopathy and found no evidence of regression of diabetic retinopathy. The extent of neovascularization was unchanged in 16 patients and there was some progression in 9 patients treated with daily injections of $20 \mathrm{mg}$ of Pegvisomant. The authors concluded that the lack of effect could be due to the improvement in overall diabetes control seen in their patients as part of pegvisomant induced improvement of insulin sensitivity and the known association of worsening of retinopathy initially with better glycemic control.

\section{Diabetic nephropathy}

In both humans and animals, GH and insulin like growth factors (IGF-I \& II) have been implicated in the development of diabetic microangiopathy which includes nephropathy and glomerulosclerosis [55]. The role of IGF system in the development of kidney disease was shown in insulinopenic diabetes model produced by Streptozotocin in rats [56]. In early experimental diabetes a transient increase in kidney IGF-1 mRNA is a consistent finding followed by renal and glomerular growth. Chen et al. [56] showed that transgenic mice expressing $\mathrm{GH}$ antagonist were protected from diabetes induced glomerulosclerosis and GH induced nephropathy. This suggested a causative relationship between elevated IGF-1 and morphological and hemodynamic changes seen with nephropathy. Studies by Landau et al. confirm that GH/IGF-1 axis plays an important role in early diabetic renal changes and specific GH antagonists could be a novel therapy to prevent diabetic nephropathy. They $[55,56]$ showed that STZ induced diabetic rats had prominent changes in IGF-1 and IGFBP gene expression with pronounced increase in IGFBP-1 mRNA in renal cortex. This increased IGFBP-1 mRNA expression causes IGFBP's to act as carriers of IGF-1 which may operate as local modulators of IGF action in various physiological and pathological conditions. The authors demonstrated an early accumulation of IGF1 in kidneys before the onset of renal enlargement and elevated GFR and renal plasma flow and suggested that there was a causal relationship between elevated IGF-1 and the morphological and hemodynamic changes. The rats then had sustained elevated levels of IGF-1 for 6 months after induction of diabetes during the development of thickening of basal membrane and elevation of urinary albumin excretion. This suggested that IGF-1 played a strong role in the patho-physiological process associated with long term diabetic renal disease It is not yet known whether Pegvisomant may have a preventative effect in development of renal lesions and end organ damage in diabetic patients or may even reverse the already existing damage.

Interestingly, Pegvisomant had no effect on renal expression of GH/IGF-1 axis proteins like IGFBP-3 and GHR in STZ induced diabetic rats. These rats when injected with daily G-120 PEG every day for 3 weeks compared to their age matched hyperglycemic counterparts, were found to have reduction in glomerular hypertrophy, GHR mRNA levels in kidney and normalization of urinary albumin excretion. Thus the GH receptor antagonist appears to have protective effects over the kidney in diabetes, preventing the development of nephropathy [56,57]. Human studies will be needed to test this hypothesis clinically.

\section{Cancer}

Two potential targets for pegvisomant therapy can be contemplated: prevention of cancer development and modification of growth of the already existing tumors. The role of IGF-1 in inducing prostate, breast and colon cancers 
has been suggested from some epidemiological studies $[58,59]$. IGF-1 is shown in experimental studies to induce the proliferation and anti-apoptotic effects of colon cancer cell lines [59]. Colon cancers constitute $18 \%$ of all cancers in acromegaly and the mechanism is thought to be the increased epithelial cell proliferation rate induced by IGF-1/ GH excess [60]. This then reduces apoptotic rate and may induce the accumulation of genetic defects leading to cancer of the colon $[61,62]$. In vivo progression and metastatic potential of human colon cancer explants were significantly inhibited in LID mice (liver specific IGF-1deficient) and both markedly increased by administration of recombinant IGF-1 [64].

IGF-1 is found to have a mitogenic and anti-apoptotic effect and is thought to have a role in inducing breast cancer particularly in premenopausal women [64]. GH receptor antagonists may be useful in this case as they can significantly reduce IGF-1 levels. Raloxifene has been shown to reduce IGF-1 levels and attenuate the development of breast cancer in women [65]. Pollack et al. [66] have also shown that $\mathrm{GH}$ antagonist transgenic mice have resistance to progression of breast tumors induced by 9, 10 Dimethyl1,2-benzanthracene (DMBA). After a 39 week treatment with DMBA, $68 \%$ of GH antagonist treated mice were without tumors as opposed to $31 \%$ of control mice. The protective effect of $\mathrm{GH}$ receptor antagonist was reversed with the administration of recombinant IGF-1.

IGF-1 is a mitogen which can increase the $\mathrm{H} 3$ thymidine incorporation in primary cultures of human meningioma cells and Pegvisomant not only inhibited the incorporation but also the growth of the human meningioma cells [67].

This clearly suggests that $\mathrm{GH}$ receptor antagonists may have a beneficial role in GH/IGF-1 dependant cancers and may reduce risk of developing these cancers.

\section{Summary}

Pegvisomant, a GHR antagonist that was introduced into the armamentarium of therapy for acromegaly is a significant therapeutic advance based on its unique mechanism of action as a peripheral GH antagonist. Unlike somatostatin analogs and dopamine agonists which bind to specific pituitary tumor receptors and act by inhibiting GH secretion, Pegvisomant acts by blocking GH action at the site of GH receptor peripherally. As a consequence, GH levels may rise and cannot be used as a marker of disease activity but IGF-1 levels are the primary measure of efficacy of therapy. The long term studies with doses up to $40 \mathrm{mg}$ /day for up to 18 months have shown normalization of IGF-1 in $97 \%$ of patients with acromegaly without development of tachyphylaxis. However the still lingering uncertainty about the potential increase in pituitary tumor size clearly requires some resolution in subsequent studies.

\section{References}

1. Melmed S. Acromegaly. The New England Journal of Medicine April 5, 1990:966-977.

2. Colao A, Ferone D, Marzullo P, Lombardi G. Systemic complications of acromegaly: Epidemiology, pathogenesis and management. Endocrine Reviews 2004;25:102-115.

3. Biermasz NR, Dekker FW, Pereira AM, Van Thiel SW, Schutte PJ, Van Dulken H, Romijn JA, Roelfsema FJ. Determinants of survival in treated acromegaly in a single center: Predictive value of serial insulin-like growth factorI measurements. Clin Endocrinol Metab 2004;89:2789-2796.

4. Holdaway IM, Stewart AW. Long term treatment outcome in acromegaly. Growth Hormone and IGF Research 2003;13:185-192.

5. Holdaway IM, Rajasoorya RC, Gamble GD. Factors influencing mortality in acromegaly. J Clin Endocrinol Metab 2004;89:667674.

6. Dobrashian RD, O'Halloran DJ, Hunt A, Beardwell CG, Shalet SM. Relationships between insulin-like growth factor-1 levels and growth hormone concentrations during diurnal profiles and following oral glucose in acromegaly. Clin Endocrinol (Oxf) 1993;38:589_ 593.

7. Barkan AL. Biochemical markers of acromegaly: GH vs. IGF-I. Growth Horm IGF Res 2004; 14(Suppl A):S97-S100.

8. Freda PU, Nuruzzaman AT, Reyes CM, Sundeen RE, Post KD. Significance of "abnormal" nadir growth hormone levels after oral glucose in postoperative patients with acromegaly in remission with normal insulin-like growth factor-I levels. J Clin Endocrinol Metab 2004;89:495-500.

9. Dimaraki EV, Chandler WF, Barkan AL. Acromegaly with apparently normal GH. Implications for diagnosis and follow up. J Clin Endocrinol Metab 2001;87;3537-3544.

10. Freda PU, Wardlaw SL, Post KD. Long-term endocrinological follow-up evaluation in 115 patients who underwent transsphenoidal surgery for acromegaly. J Neurosurg 1998;89:353-338.

11. Freda PU, Post KD, Powell JS, Wardlaw SL. Evaluation of disease status with sensitive measures of growth hormone secretion in 60 postoperative patients with acromegaly. J Clin Endocrinol Metab 1998;83:3808-3816.

12. Melmed S, Casanueva FF, Cavagnini F, Chanson P, Frohman L, Grossman A, Ho K, Kleinberg D, Lamberts S, Laws E, Lombardi G, Vance ML, Werder KV, Wass J, Giustina A. Guidelines for acromegaly management. Acromegaly Treatment Consensus Workshop Participants. J Clin Endocrinol Metab 2002;87:4054-4058.

13. Abosch A, Tyrrell JB, Lamborn KR, Hannegan LT, Applebury CB, Wilson $\mathrm{CB}$, Transsphenoidal microsurgery for growth hormonesecreting pituitary adenomas: Initial outcome and long-term results. J Clin Endocrinol Metab 1998;83:3411-3418.

14. Swearingen B, Barker FG 2nd, Katznelson L, Biller BM, Grinspoon S, Klibanski A, Moayeri N, Black PM, Zervas NT. Longterm mortality after transsphenoidal surgery and adjunctive therapy for acromegaly. J Clin Endocrinol Metab 1998;83:3419-3426.

15. Biermasz NR, van Dulken H, Roelfsema. Long-term follow-up results of postoperative radiotherapy in 36 patients with acromegaly. J Clin Endocrinol Metab 2000;85:2476-2478.

16. Biermasz NR, Dulken HV, Roelfsema F. Postoperative radiotherapy in acromegaly is effective in reducing GH concentration to safe levels. Clin Endocrinol (Oxf) 2000;53:321-327.

17. Vladyka V, Liscak R, Simonova G, Urgosik D, Chytka T, Vymazal J, Novotny J, Marek J, Hana V. Gamma Knife (GK) radiosurgery 
for pituitary adenomas: Evaluation of a series of 163 patients. $J$ Radiosurg 2000;3:113-131.

18. Barkan AL, Halasz I, Dornfeld KJ, Jaffe CA, Friberg RD, Chandler WF, Sandler HM Pituitary irradiation is ineffective in normalizing plasma insulin-like growth factor I in patients with acromegaly. $J$ Clin Endocrinol Metab 1997;82:3187-3191.

19. Barkan AL. Radiotherapy in acromegaly: The argument against. Clin Endocrinol 2003;58:132-135.

20. Ayuk J, Clayton RN, Holder G, Sheppard MC, Stewart PM, Bates AS. Growth hormone and pituitary radiotherapy, but not serum insulin-like growth factor-I concentrations, predict excess mortality in patients with acromegaly. J Clin Endocrinol Metab 2004;89(4):1613-1617.

21. Brada M, Ford D, Ashley S, Bliss JM, Crowley S, Mason M, Rajan $\mathrm{B}$, Traish D. Risk of second brain tumour after conservative surgery and radiotherapy for pituitary adenoma. Br Med J 1992;304:13431346.

22. Swords FM, Monson JP. Stereotactic radiosurgery: A treatment for previously radiated pituitary adenomas. J Clin Endocrinol Metab 2003;88:5334-5340.

23. Attansio R, Arosio M. Gamma knife radiosurgery in acromegaly: A 4 year follow up study. J Clin Endocrinol Metab 88:3105-3112.

24. Jaffe CA, Barkan AL. Treatment of acromegaly with dopamine agonists. Endocrinol Metab Clin North Am 1992;21:713-735.

25. Abs R, Verhelst J, Maiter D, Van Acker K, Nobels F, Coolens JL, Mahler C, Beckers A. Cabergoline in the treatment of acromegaly: A study in 64 patients. J Clin Endocrinol Metab 1998;83:374-378

26. Freda PU. Clinical Review: Somatostatin analogs in acromegaly. $J$ Clin Endocrinol Metab 2002;87:3013-3018.

27. Colao A, Ferone D, Marzullo P, Cappabianca P, Cirillo S, Boerlin V, Lancranjan I, Lombardi G. Long-term effects of depot long-acting somatostatin analog octreotide on hormone levels and tumor mass in acromegaly. J Clin Endocrinol Metab 2001;86:27792786.

28. Colao A, Marzullo P, Ferone D, Marino V, Pivonello R, Di Somma C, Di Sarno A, Giaccio A, Lombardi G. Effectiveness and tolerability of slow release lanreotide treatment in active acromegaly. J Endocrinol Invest 1999;22:40-47.

29. Burt MG, Ho KK. Comparison of efficacy and tolerability of somatostatin analogs and other therapies for acromegaly. Endocrine 2003;20:299-305.

30. Barkan AL, Kelch RP, Hopwood J, Beitins IZ. Treatment of acromegaly with long acting SMS 201-995. J Clin Endocrinol Metab 1988;66:16-23.

31. Van der Hoek J, de Herder WW, Feelders RA, van der Lely AJ, Uitterlinden P, Boerlin V, Bruns C, Poon KW, Lewis I, Weckbecker G, Krahnke T, Hofland LJ, Lamberts SW. A single-dose comparison of the acute effects between the new somatostatin analog SOM230 and octreotide in acromegalic patients. J Clin Endocrinol Metab 2004;89(2):638-645.

32. Ho PJ, Freiberg RD, Barkan AL. Regulation of pulsatile growth hormone secretion by fasting in normal subjects and patients with acromegaly. J Clin Endocrinol Metab. 1992;75:812-819.

33. Ho KY, Veldhuis JD, Johnson ML, Furlanetto R, Evans WS, Alberti $\mathrm{KG}$, Thorner MO. Fasting enhances growth hormone secretion and amplifies the complex rhythms of growth hormone secretion in man. J Clin Invest 1988;81:968-975.

34. Clemmons DR, Underwood LE, Judson J. Van WykJJ. Estradiol treatment of acromegaly. The American Journal of Medicine 1980;69:571-577.

35. McCarthy M. Estrogen agonists/antagonists downregulate GH. Medical Hypotheses 2003;61:335-339.

36. Leung KC, Doyle N, Ballesteros M, Sjogren $\mathrm{K}$, Watts $\mathrm{CK}$, Low TH, Leong GM, Ross RJ, Ho KK. Estrogen inhibits
GH signaling by suppressing GH-induced JAK2 phosphorylation, an effect mediated by SOCS-2. Proc Natl Acad Sci USA 2003;100(3):1016-1021.

37. Attanasio R, Barausse M, Cozzi R. Raloxifene lowers IGF-1 levels in acromegalic women. Eur J Endocrinol 2003;148:443-448.

38. Dimaraki EV, Symons KV, Barkan AL. Raloxifene decreases serum IGF-I in male patients with active acromegaly. Eur J Endocrinol 2004;150:481-497.

39. Chen WY, Wight DC, Mehta BV, Wagner TE, Kopchick JJ. Glycine 119 of bovine growth hormone is critical for growth-promoting activity. Mol Endocrinol 1991;5:1845-1852.

40. Kopchick JJ, Parkinson C, Stevens EC, Trainer PJ. Growth hormone receptor antagonists: Discovery, development, and use in patients with acromegaly. Endocr Rev 2002;23:623-646.

41. Kopchick JJ, Okada S. GH receptor antagonists: Discovery and potential uses. Growth Horm IGF-1 Res 2001; (Suppl A):S103S109.

42. Okada S, Kopchick JJ. Biological effects of GH and its antagonist. Trends in Molecular Medicine 2001;7:126-132.

43. Trainer PJ, Drake WM, Katznelson L, Freda PU, Herman-Bonert V, van der Lely AJ, Dimaraki EV, Stewart PM, Friend KE, Vance ML, Besser GM, Scarlett JA, Thorner MO, Parkinson C, Klibanski A, Powell JS, Barkan AL, Sheppard MC, Malsonado M, Rose DR, Clemmons DR, Johannsson G, Bengtsson BA, Stavrou S, Kleinberg DL, Cook DM, Phillips LS, Bidlingmaier M, Strasburger CJ, Hackett $\mathrm{S}$, Zib K, Bennett WF, Davis RJ.Treatment of acromegaly with the growth hormone-receptor antagonist pegvisomant. $N$ Engl J Med 2000;342:1171-1177.

44. Drake WM, Parkinson C, Besser GM, Trainer PJ. Clinical use of GH receptor antagonist in treatment of acromegaly. Trends Endocrinol and Metab 2001;12:408-413.

45. Stewart PM. Pegvisomant: An advance in clinical efficacy in acromegaly. Eur $J$ Endocrinol 2003;148(Suppl 2):S27S32.

46. Muller AF, Kopchick JJ, Flyvbjerg A, van der Lely AJ. Clinical review 166: Growth hormone receptor antagonists. J Clin Endocrinol Metab 2004;89:1503-1511.

47. Van der Lely AJ, Hutson RK, Trainer PJ, Besser GM, Barkan AL, Katznelson L, Klibanski A, Herman-Bonert V, Melmed S, Vance ML, Freda PU, Stewart PM, Friend KE, Clemmons DR, Johannsson G, Stavrou S, Cook DM, Phillips LS, Strasburger CJ, Hackett S, Zib KA, Davis RJ, Scarlett JA, Thorner MO. Long-term treatment of acromegaly with pegvisomant, a growth hormone receptor antagonist. Lancet 2001;358(9295):1754-1759.

48. Trainer PJ, Drake WM, Perry LA, Taylor NF, Besser GM, Monson JP. Modulation of cortisol metabolism by the growth hormone receptor antagonist pegvisomant in patients with acromegaly. $\mathrm{J}$ Clin Endocrinol Metab 2001;86(7):2989-2992.

49. Parkinson C, Drake WM, Wieringa G, Yates AP, Besser GM, Trainer PJ. Serum lipoprotein changes following IGF-I normalization using a growth hormone receptor antagonist in acromegaly. Clin Endocrinol (Oxf) 2002;56(3):303-311.

50. Veldhuis JD, Bidlingmaier M, Anderson SM, Wu Z, Strasburger CJ. Lowering total plasma insulin-like growth factor I concentrations by way of a novel, potent, and selective growth hormone (GH) receptor antagonist, pegvisomant (B2036-peg), augments the amplitude of GH secretory bursts and elevates basal/nonpulsatile $\mathrm{GH}$ release in healthy women and men. J Clin Endocrinol Metab 2001;86(7):3304-3310.

51. Drake WD, Trainer PJ. Insulin sensitivity and glucose tolerance improve in patients with acromegaly converted from depot octreotide to pegvisomant. Eur J Endocrinol, 2003;149:521-527.

52. Clemmons DR, Chihara K, Freda PU, Ho KK, Klibanski A, Melmed S, Shalet SM, Strasburger CJ, Trainer PJ, Thorner MO. Optimizing 
control of acromegaly: Integrating a growth hormone receptor antagonist into the treatment algorithm. J Clin Endocrinol Metab 2003;88:4759-4767.

53. Smith L, Schaeffer J. Essential role of GH in Ischemia induced Retinal neovascularization. Science 1997;276:1706-1708.

54. Beck R, Ellis K. The effect of Growth hormone receptor antagonist drug on proliferative diabetic retinopathy. Ophthalmology 2001;108:2266-2272.

55. Landau D, Chin E, Bondy C, Domene H, Roberts CT, Gronbaek H, Flyvberg A, LeRoith D. Expression of Insulin like Growth Factor binding proteins in the rat kidney: Effects of long term diabetes. Endocrinology 1995,136:1835-1842.

56. Chen N, Kopchick JJ. Effects of Streptozotocin treatment in GH and GH antagonist transgenic mice. Endocrinology 1995;136:660667.

57. Segev Y, Landau D, Rasch R, Flyvbjerg A, Phillip M. Growth hormone receptor antagonism prevents early renal changes in nonobese diabetic mice. J Am Soc Nephrol 1999;10:2374-2381.

58. Bengtsson BA, Eden S, Ernest I, Oden A, Sjogren B. Epidemiology and long term survival in acromegaly. A study of 166 cases diagnosed between 1955 and 1984. Acta Endocrinol 1988.223:327335.

59. Barzilay J, Heatley GJ, Cushing GW. Benign and malignant tumors in patients with acromegaly. Arch Intern Med 1991;151:1629_ 1632.
60. Blakesley VA, Stannard BS, Kalebic T, Helman LJ, LeRoith D. Role of the IGF-I receptor in mutagenesis and tumor promotion. $J$ Endocrinol 1997;152(3):339-344.

61. Ma J, Pollack MN, Giovannucci E, Chan JM, Tao Y, Hennekens CH, Stamper MJ. Prospective study of colorectal cancer risk and plasma levels of insulin like growth factor and IGF- binding protein-3. $J \mathrm{~N}$ Cancer Inst 1999;91:620-625.

62. LeRoith D, Roberts CT Jr. The insulin-like growth factor system and cancer. Cancer Lett 2003;195(2):127-137.

63. Wu Y, Yakar S, Zhao L, Hennighausen L, LeRoith D. Circulating insulin-like growth factor-I levels regulate colon cancer growth and metastasis. Cancer Res 2002;62(4):1030-1035.

64. Furstenberger G, Morant R, Senn HJ. Insulin-like growth factors and breast cancer. Onkologie 2003;26:290-294.

65. Torrisi R, Baglietto L, Johansson H, Veronesi G, Bonanni B, Guerrieri-Gonzaga A, Ballardini B, Decensi A. Effect of raloxifene on IGF-I and IGFBP-3 in postmenopausal women with breast cancer Br J Cancer 2001;85:1838- 1841.

66. Pollak M, Blouin MJ, Zhang JC, Kopchick JJ. Reduced mammary gland carcinogenesis in transgenic mice expressing a growth hormone antagonist. Br J Cancer 2001;85:428-430.

67. McCutcheon IE, Flyvbjerg A, Hill H, Li J, Bennett WF, Scarlett JA, Friend KE. Antitumor activity of the growth hormone receptor antagonist pegvisomant against human meningiomas in nude mice. J Neurosurg 2001;94(3):487-492. 